Universidad de Lima

Facultad de Derecho

Carrera de Derecho

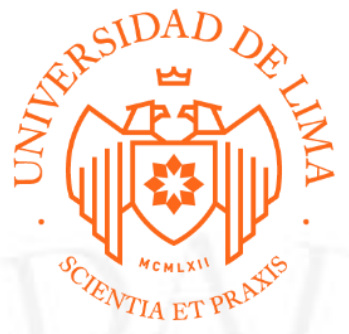

\title{
ARBITRAJE: "ARBITRAJE INSTITUCIONAL DE DERECHO" Y ADMINISTRATIVO: "COMPETENCIA DESLEAL"
}

Trabajo de suficiencia profesional para optar el Título Profesional de Abogado

César Alexander Riveros Torres

Código 20081738

Lima - Perú

2019 


\section{ARBITRAJE: "ARBITRAJE INSTITUCIONAL DE DERECHO" \\ Materia: Arbitraje Institucional de Derecho \\ $\mathrm{N}^{\mathrm{o}}$ de Expediente: $324-3-2013$}

\section{RESUMEN}

El presente Expediente contiene los actuados en el marco de un Arbitraje Institucional de Derecho, cuyo objeto de la controversia es que el Tribunal Unipersonal determine si corresponde o no dejar sin efecto la penalidad aplicada por A. A. S.A. (Demandado) a B. B. S.A. (Demandante).

ADMINISTRATIVO: "COMPETENCIA DESLEAL"

Materia: Competencia Desleal

$\mathrm{N}^{\mathrm{o}}$ de Expediente: $0040-2015 / \mathrm{CCD}$

RESUMEN

El presente Expediente contiene los actuados en el marco de un Procedimiento Administrativo Especial iniciado de Oficio por la Secretaría Técnica de la Comisión de Fiscalización de Competencia Desleal del ente regulador INDECOPI (Denunciante), en contra de C. C. S.A.C. (Denunciado), en donde finalmente corresponderá que en Segunda Instancia, sea la Sala Especializada en Defensa de la Competencia, quien determine si Productos del Horno cometió o no actos de competencia desleal en la modalidad de engaño al haber consignado en el empaque del producto "Brownie Marmoleado con Castañas”, la afirmación “0g Grasas Trans por porción”. 